\title{
蘇聯基本科盥著作的翻譯工作 中的幾個問題
}

\section{評葉藴理譯布洛欣朵夫著“量子力學原理”}

\author{
襲 有之
}

榮獲1951年斯大林獎金的布洛欣策夫著 “量 子力學原理”一書的中譯本, 已經由商務印書舘於 1952年出版了。们洛欣采夫的書, 是一本好書, 誠 如斯圖乞克所詐“慗破唯心論, 確泣唯物論, 這是 自然科學的晢學领域內一個中心的任務”。布洛欣 采夫的著作, 對於配合量子力學來解决這一問題, 是一個成功的嘴試。它並不只是量子力學方面的 又一個数本, 而是在其中成功地筫現了“站在正確 的唯物論立場來講述量子力興”的這樣一個企圆 的著作。縱然賟有一些像蘚聯的訐論家所指出的 這本書在某些方面的调別缺知(1)，但總的說來，是 大家異口同馨，歡迎這本書的出版的。我們不预 備在這裹吅論造本書本身, 讀者可以去參看斯㖥 乞克的訐論 $(2)$, 他出色地做了這一件工作。我們 淮備來談談造僻譯本的翻譯, 並且進一步談談閔 於蘇聯基本科學書籍的翻譯工作中的㙨储問題。

當前在我們迎接即將到來的大規模經僦建设 和交化建設, 篇國家工業化而鹪鬥的任務當中, 科 學研究和科學敉學的工作, 佔着一席重要的地位。 第了腾利地完成這一偉大任務, 我們的科學研究 和科學敉學工作必须進行、也正在進行改革。而學 棔蘇聯先進科學，則是進行改革的首要關鍵。所 以,萑聯科學書籍的翻譯, 是一件十分迫切而重要 的工作, 這件工作, 特別是其中的敉科書的翻譯工 作的迫切性和重要性, 由於全國高等學校院系調
整的䨘行而更明顛地表現出來了。人民日報會緼 一再指示我們, 它說目前只是“高等教高徽底改革

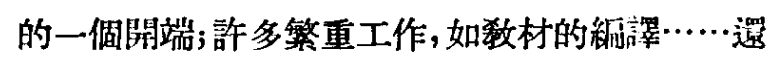
需要全國敉育工作者䊽續以最大的努力來完成。” （人民日報 1952 年9月 24 日到論）“迫切需要翻摆 大量的鮛聯教材和課本，因此如何統一組織和指

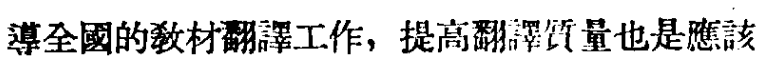
十分注意的一㑑閣題”。(人民日報 1952 年 12 月 1 日頭條報㝵)

解放以來,我們也介釈了一些魴聯科學。但從 譯出來的材料來說, 單篇論文、小册子居多，基本 科學著作察客可數。

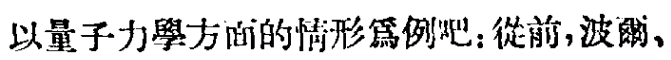
海森堡等人的主觀的唯心的觀點, 在我們的科學

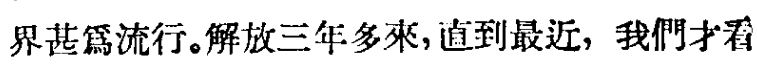
到幾篇有系統地批制量子力學中的唯心論 的論

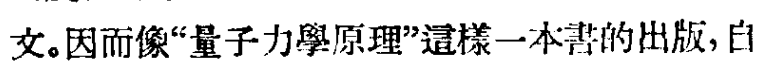
然受到我們科學界的廣泛的鹳迎和重視。這些输 文和書籍的譯文的發表與出版, 顛然已䋑在我侣

(1) 例如，馬克西莫夫通訊院士作討綸化學檽造理

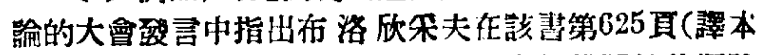

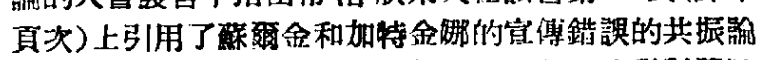

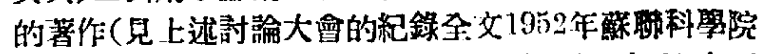

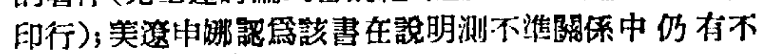

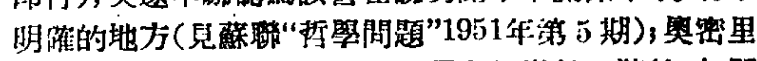

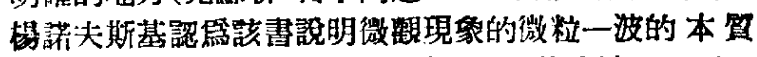

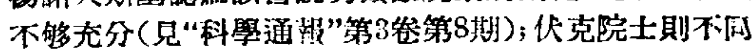

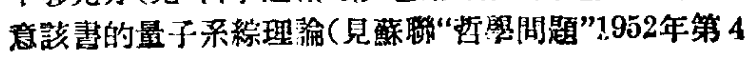
期)。

(2) 載“㓔䔐月報”1952年第 6 期。 
的科學界開始破生了影響。

我們在這裹强調蘇聯基本科學著作的翻譯。

因第, 運一類基本的重要的科學專著的翻譯, 䫏 然是更其重要的工作。只有把這種基本的重要的 工作做好了，等聯科學介紹才能在我們的科學研 究與科學敉學中真正扎下根深带固的基礎。我們 並不輕視單篇論文和小册子的介釈，一點也不整 視，相反地，我們還認絾它們具有特别的優點, 即 戰鬥中的特殊靈活性。但是,單篇論交和小册子的 介紹，對於我們科學研究與科學数學的改革工作 的影響是有限的。一個認艮的、勤勞的科學工作 者是不能就此滿足的。

過去大部頭的基本書籍之所以介紹得不够， 賞然有其本身的困難存在。第一, 這類專門書籍, 不是一般科學知識不够的翻紧工作者所能翻譯， 必須專家親自動手, 至少要在專家的漞自指導下 戈能進行; 而蒷俄文的專家過去又還不多。第二, 這類書籍一般都是篇幅很大, 洋洋數十萬言, 如果 猲譯,少則本年,多則一载爾載。如果不認識這種工

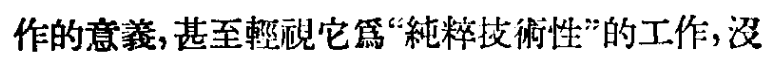
有賁徽到底的毅力, 那是翻㘁不出這類的書籍的。

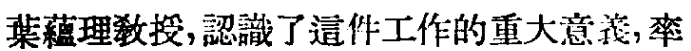

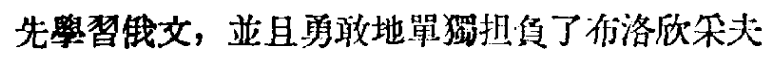
道本五十萬言的重要巨著的翻譯工作, 這一點, 是 㑤得我們感謝的。

現在, 配合着高等数育的改革工作, 全國許多 数授、員同志抱着極大的愛國熱情, 在很短的 時期內突謷學會了俄文票業書籍閱讀, 並且正在 大規模地、迅速地、有計劃地、而且是辛勤地翻翋 着独聯的科書籍, 他們的熱情和工作是令人十 分感動和敬佩的。我們熱烈地預祝他們這件工作 的成功, 堅信他們一定成功。

\section{$\equiv$}

但是,十分令人惋惜的是，葉䒸理的譯本，從 解䍘方面䛦, 是完全不能令人滿意的。

我們校致了該譯本上册的導夆、第一章、第二 章，以及以後第三章到第十二竞中各音的一小笁 和兩小節; 總計校讀了120頁, 佔上册 348 頁的三分 之一以上。又校讀了該譯本下册的第十儿第二 十二章和總結, 共計 70 頁, 佔下册352頁的五分之 一. 合計校讀全書四分之一以上。其中錯衫之多,
是令人吃等的。以錯誤較多的拿言和總結第例, 前 者共 3 頁，本均每頁的錯筑在五處以上，後者共21 頁, 平均每頁錯誤三處以上。以錯誤並不是䫅著地 特別多的第十九章第例，22面中只有 8 頁汥有较 大的錯融，其他14页每面至少一處錯誤。以上所請 “錯兒”，還不算那些比較無關緊要、但對原文說來 畢㾞要算是錯㟝的地方。

除了錯韶特多這一嚴重缺點之外，䒚譯本的 另一嚴重缺點便是中文語法不通，修筒拙出少。大部 份的交字都極篇警拂以至文㼁会糊不清。這核的 例子是無法枚舉的,下面所鼠的譯錯的例子，我 全都又是文字拙劣的例子。

現在我們稍微舉幾储例子看看吧!

1. 第 3 面 $(11$, 這是原文项次, 下同)上 “因此 量子力學研究微粒子的統計集合和測量宏觀的儀 器的關係, 用這些儀器可以確定所謂 “粒子的情 態, 即定賞統計集合"。

逜裹，譯者剖好把一句唯物的制斷正曲成一 句唯心的判断了。大家知道，綪着量子力學研究 對象的問題, 正進行着唯物論與唯心論的弫争。唯 物諭者認第微粒:子本身是可知的, 我們用儀器作 篇一種研究的工具去認識不依顿於儀器测量而存 在的微粒子, 唯心論者則認䈔微粘子是不可知的, 儀器在認識微粒子的過程中, 除了作第研究工具 的作用之外,還起着一種特殊的作用: 测星改變了 微粒.子狀熊, 因此, 似乎我們所能知羊的只是微 粒.子與宏觀儀器的關係, 而不是微粒子子本身, 我們 對於微粒子的知識具有一種公觀性。希洛欣采夫 這本書的重要貢㱆之一, 即在於他粉碎了“微粒.子 不可知”的唯心的論調。譯者似乎並涩有注意到道 一點, 而粗枝大葉地把原文歪朋了。這裹, 布洛欣 朵大本來是說: “因此, 量子力學是在微粒子于與宏 觀的測量儀器的關係之中來研究微粒子的統計集 合(系棕), 用這些儀器可以測定所謂 “粒子的狀 態, 即可以確定統計的集合。”

2. 第1頁 (9)上“單純而基本的粒子的特徽是 具有完全確定的標誌 (電荷、質量等等), 這對於每 一種粒子都是相同的。”

難道,電子和質子的質量相同?質子和中子的 電待相同?智然不是這樣。譯者在這異把“這對於 同一種類的全部粒，都是相闹的”給譯成“這對於 繁二種粠都是相问的了”。 
3. 第 2 頁 $(10)$ 上“把 “柆子”造個名詞應用在 微憼世界中的倜體上, 這在我們的觀念中引起的 是它活像古興力學的物質點, 但不像後者待合賽 際。”

“後者”是指的誰?又怎樣不符合䐝際? 原來， 作者的意思是詮:“用粒.子逭個字來表示微憼世界 中的倜體，倒更容易使我們把它類比於古典力學 中的物質點, 而不容易使我們想像 到實 際的情 形。”

4. 第 3 頁(10)上“在古典統計力學的基礎上 建立了牛頓力學, 可以描述每一顆粒子的歷史, 好 像在原则上是可能把每一個别的樣子作一遍傳記 似的。”

用不着看原文, 只須稍微想一想, 就會知道, 譯者是把原文完全方修䫖倒了。原文是“經典的統計 力學是以牛頓力學篇基礎的, 牛頓力學認第可 以…...”。"

5. 第7頁 (14) 上“照波動理論, 入射的振幅將 分篇透射的和反射的波。”

這真是令人無法瞭解的譯文。作者完全滩有 說過什麼振幅變篇波,他是說: “根據波動理論, 入 射波、透射波、反射波的振幅將要不同。”

6. 第17页 (23)上"反之, 由量子理論的觀點， 原子受了限界內外加作用的，可以認第具有三個 自由度的客體。”

原文是: “反之，從量子理論的觀點看來，原子 在相當廣的範嘻內, 實際上可以看作僅僅具有三 调自由度的客體。”受了限界內外加作用的”幾個 字在原交中根本找不到。

7. 第23頁 (28) 上 “愛因斯坦微分係數。它 椚只依赖系統的性質, 輻射的和吸收的光的性 質, …...”

譯者在造赛汥有委清俄文自動形動詞短語的 用法, 原文應䠹是: “它們只依赖於輻射和吸收光 線的系統的性筫。”經過譯者一改,一個條件變成 三個了。

8. 第 24 頁(29)上“通常任何量子水平 $E n$ 多 少適合量子系統的一種情態。這種情態的數目 $\dot{f} n$ 叫做統計權數或退化度數。

“依照正则分佈律, 在古典菜統中正如在量子 系統中，在具有能量 $E n$ 的情態下的原子數 $N n$ 等

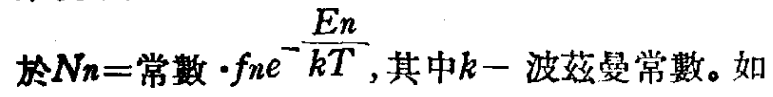

果我們關心的是原子數 $\boldsymbol{n} n$, 它們在任何一種情態 下而具有能量 $E_{n}$ ，则根據同樣的分佈律將是 $\dot{n n}_{n}$ $=\frac{N n}{f n}=$ 常數. $e^{-\frac{E n}{k T}}$."

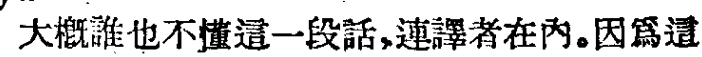

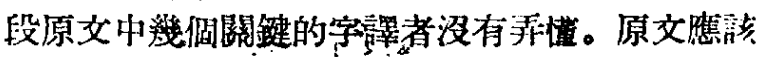
是:

“通常量子系統可以有幾個不同的狀態一同

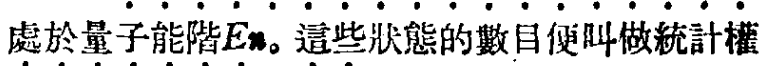
数或退化度数。

“根提對於經典系統和量子系統都是正確的 正則分佈律, 處於具有能量 $E n$ 的諎敞態中的原子 總數目 $N n$ 等於 $N n=$ 常數 $\cdot f n e^{-\frac{E n}{k T} \text {, 此處 } k \text { 是 }}$ 波茲曼常數。如果我們只洘虑處於具有能量 $E n$ 的 某一種情態中的原子数目 $n n$, 那照根據司上的分 配律, $n_{n}=\frac{N_{n}}{f n}=$ 常數 $\cdot \frac{-E_{u}}{k T}$ 。”

9. 第35广 (38)上“在這湖方法中起始電子通 過相党深的装片, 它具有多晶體結構, (第避硕電 子被强然地吸收，這装片要很溥才行，的近 $10^{-5}$ 厘米)。”

“相”篦厚”而又“很薄”的藮片，大概不見得可

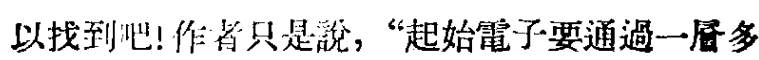

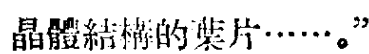

10. 第39门(42)上“這種對於斗布洛衣波的瞭 解是具有完全占典性質的。逭事的根搌是來於造 㑬情况: 可以證明(在理論上)在一切粠子的例中， 可以建立一種波泿的形式，它的振動等合粒子的 運動，而这粒子按照古典力學運動。”

真的可以“在一切粘子的例了中”都證明是逜 樣嗎? 作者只是說, “在某些非常倒别的㤽况下”, 才可能證明。

11. 第43頁 (45)上“斑點或者縫的坐標可用三 個獨立的標度來確定。滈種坐標測定我們叫作 'IE 交”坐標，正如在宏觀的運動中確定粒子坐標的 概念也是建立在造做測量法上的。”

其實是,“玟點或者縫的坐標可以用剛體的尺 來测量。這種坐標测量我們叫“㐤接的”测量, 因第 粒了坐標概念的宏觀定義便是建立在這種測量之 与的。”譯者雖然在下面馬上又改正了, 稱之篇“淔 接的”賽驗了, 但在這倜地方彻仍然令人很奇怪地 稃作“正交”坐標。

12. 第53面(54)上“由已知的波函數做一種顾 
言，正如一般統計學䪱言，只能通過很多次数的可

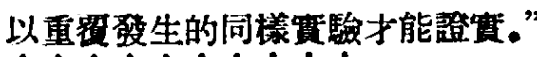

什然叫做“可以重徣發生的同樣實驗”9 是不 是指經過同樣的菑驗操作，不同次数的萲驗結果 完全一㮹? 如果逢樣及何必要統計學? 作者只是

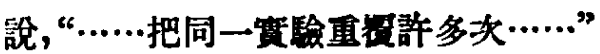

13. 第58頁(58)上“在古典力學中, 我們可任 意地提出問題。”

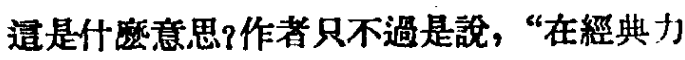
學中,討論到粒子的運動時, 我們可以用另外的一j 式提出問題。”。

14. 第66面(65)上“第定當起見，試用粒子的 一個坐標，例如 $y$ 。第此，在楗的平面上樹立一倜 屏.......”

原文是: “我們來固定粒子的一個坐標, 例如

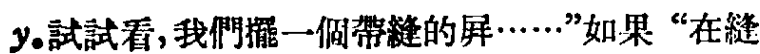
的平面上樹立一倜屏”, 又怎樣來“定當” $y$ 坐標呢?

15. 第116面(109)上“現在我們假定，從 $t=0$ 到任意時 $t$ 的過程中做任何測量, 而就情態的戀 更而言，僅僅地是粒子本身 (或粒子系統) 蓮動， 不受測量儀器的干摄。”

就我們所知, 對粒子進行測量時, 儀器與粒子 之間便發生了相互作用,或者說發生了“干摄”, 不 可能做了“任何測量”而粒子運動並不受儀器的干 㨡”。作者的意見也是這樣的,他說: “現在我們假 定從 $t=0$ 到某一瞬時 $t$ 譄段時間間隔內沒有淮 行任佦測量, 那遮這就是說, 妆態的變化僅僅是 由於粒文(或粒子系梳)的運動所引起的, 並汥有 受測量儀器的干擾。”

16. 第158頁 (141) 上 “所有的振幅 $C_{n}(t)$ 又 完成確定 $\psi(x, t)$ 的任䅂。反之, $\psi(x, t)$ 的任務是 確定 $C n(t)$ 。”

原交是: “給定所有的振幅 $C_{n}(t)$ 便能完全確 定 $\psi(x, t)$ 。反之, 給定 $\psi(x, t)$ 也能確定 $C_{n}(t)$ 。”

17. 第540頁 (449)上“交換算符 $P_{k j}$ 的本街洒 數是一種国數, 它在交換第 $k$ 粒子的坐標 $\left(q_{k}\right)$ 和 第 $j$ 粒子的坐標 $\left(q_{j}\right)$ 時既不改稤 (111.5) 又不改 整他的反躆的(111.6)。”

其實，原交是: “在交換 $\left(q_{k}\right)$ 和 $\left(q_{j}\right)$ 時,塄個函 数，或者不起答化，如 (111.5)，或者要反一反符 栫, 如(111.6)。”

就在䢧段引文下面三行, 我們及遇到同樣的
一们，而这這一创，譯者卻譯得很正確。

18. 第625页 (521) 上, 談到用經典理論解决间

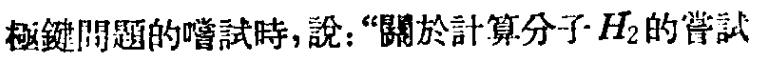
從來汥有達到涩意的結果。由在上面所說明的分 $\gamma \cdot H_{n}$ 的量子-理諭䫏然也存在這種失敗…..."

我們知道，量子一理論基本上解决了同極鍵的 閆題, 原文是說: “從上面所說明的分子 $H_{z}$ 的量 子理論看來, 這些失敗的原因是很明白的了…。”

19. 第658页 (549) 上, “原子的量子水次的發 現, 以及它們的薄片的和最後在薄片表面的結㮖 （相當的能量的差别約近 $10^{-12}, 10^{-15}$ 和 $10^{-18}$ 厄 格) , …..”

原交完全汥有說什磨 “溥片的和在薄片表面 的結構”，而是說: “原子的量子能階的發現，慥 後其精細結構的發現, 最後其超梢細結 構的 現……”

20. 第661项(552)上,談到受因斯坦和波的的

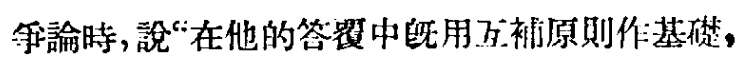

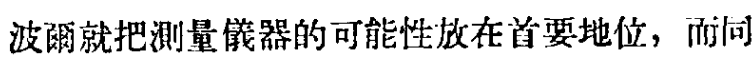
時認第主裂的事就是結論測量的客能的新性啠:

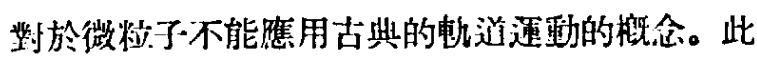
外，波爾停留在對波函數作統計的解釋的一㟟。”

恰恰相反，原文是說: “波雨既然以並協原则 篇其答禞的基礎, 他就把測量㕠器的可能性提外 到第一位，然而問題的林質卻在於测量客能- 微粒子子的新性睤, 經典的顿道運動概念不能應用 在微粒子上。波爾把波函數的統計的解釋执在 一邊。”

以上不過是順手舉出來的一些特別斯著的例 子一而已，其他如“强度”譯成“解釋”，“存在”變成 “重要”，“舊”變成“方面”，“答化”譯成“測量”， (這些都不過是因篇字形略微有點相似)。“發現” 變成“發明”。“研究”變成“检討”, “是”變成“朴留 上”, “二十年代”變成“二十年中”, 肯定變成否定, 原因變成結果, “左”變成“右”，“連櫝”變成“锌 縜”，特別是由於把第二格譯錯，“波的骨合”變成 “嶨合的波”, “光底散射”變成“枚射光”，“波的運 動”變成“運動中的波”, “能量的量子化”變成“量 子能量”, 再加上單複數的錯誤, 代名詞的混儌，字 句的脱漏, 可以想見, 這部譯本是名副其賽的鉷誤

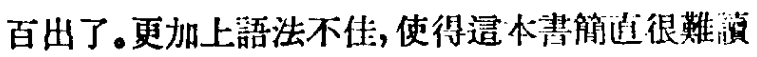


浩成通椪的情况的原因, 我們以第, 首要的並 不是摆者的水平低, 而是譯者的態度不認真。

梁䔉理先生是大學物理學敉授, 絕不能說, 上 面所舉的症明了科學內容的譯例，是譯者不笹科 學的結果。同樣的句子, 同一個字, 譯者常常在前 酸摆鍇了，在後面另一處地方又譯對了; 甚至同一

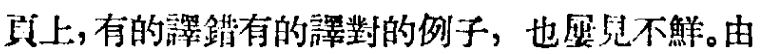
此可思, 以㩐者的俄文水本來說, 本來應該可以 減少一些錯留。

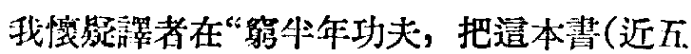
一个萬字!一一体交作者註）䞨譯成功”（兒摆者序 言)光後, 是否自己校閲過一游。如果校閲過的話，

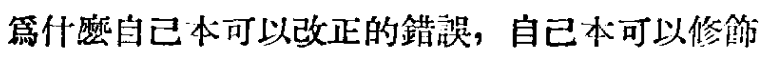
通順的问子，浔有改過來，沼有修飾好? 如果浑有 校閱, 這樣的工作態度又何壦設想?

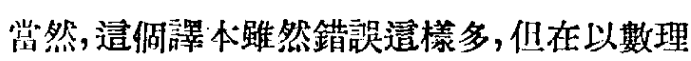
公式的推算篇主的那些部份, 錯誤到底是較少的, （但决不是浔有）而造樣的部份在這本書中所佔的 比重文不算很小，因此，它對於不懂俄文的讀者， 終於不無谷致。但是, 我們相信，汥有一㑬讀者會 㴖足於這榡的譯本。

譯者在“譯者序言”中表示願意聴取讀者意

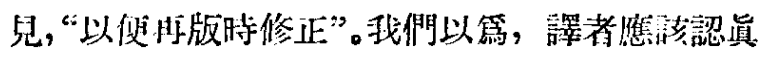
地把這本譯本從䌿到尾，一個字一個字地對照原 交再校正一通，重新排印; 如果能找到别人怔校閱 一次更好。並且，篇了補傥第一版的讀者起見，應 該印一册勘誤表, 勘正重要的錯误, 迩給讀者・

想必譯者和出版者不會拒絕這樣做。

\section{四}

有洛欣尔夫的“量子力學原理”（以及這一類 的書)梌其需姴翻澤出來, 但現有的譯本却植不能 命人滿意, 狺是令人婉惜的事。現在, 正當我們在 大規模翻澤敎科萧的時候，從事翻澤工作的人又 大都只受過短期的俄文禁業阔讀訓練，而任務卻 很急迫, 在這漛的情况下, 從渠譯本的失敗中記取

一些收訓, 是很必要的。

我們應融記取一些什麼敉訓呢?

首先, 最重要的, 還是一偑工作態度問題。如 果想到自己所担當的就是介紹蘇聯先進科學的菲

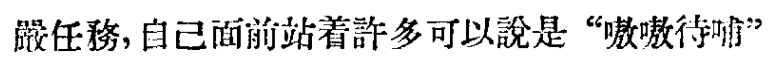
的讀者, 急於拜讀你的譯文, 那你便不能不認前地
兢莌業業地工作。如果忘了這一點，只看见丁頕的

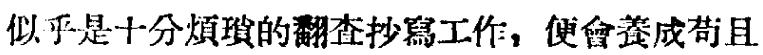
偷性、馬馬卧虎、完成數字任務了事的作風。必須 和造種作風進行不嶵的鬥争。

在翻譯中, 遇到不認䇅的字, 或者汥有把握的 字，就必须翻字典、查清楚! 遇到不懂的句于，或者 模糊不清的句子, 就必須仔細分析其文法, 愁明 白。如果實在查不到, 严不明白, 就隼去請敎别人。 翻譯不比閱莜, 閱讀時馬虎一點不過是自己一個 人少知道了一點, 翻諲時馬虎一點便是伱心些琵 大量讀者。偷攋、馬虎、以意篇之、含糊混䮦、以猜 想代替查考、以杜拸代替推敲、……這些, 認是 說桃, 都是罪過。

闹時, 也惟有認资對待弱難地方，在解决疑難 之中正能迅速進步, 才會越來越少碰胃张難地方, 才能使翻譯質量提高, 翻譯速度加快。碰到钲難健 馬虎過去，則永遠不能進步，那就成了翻譯老油

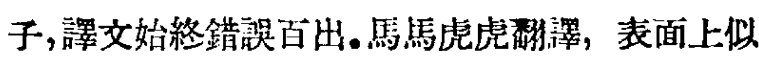
乎是快了，其結果是産生了度品，全盤浪殞，速度 等於貨。求快的關鍵在於提高水平.

端正了態度之後, 才可以瀞求方法, 我們以 篇, 對於科學書籍的初譯者說來, 應該强調雨方 面:

第一: 交法與字致是語言的基礎, 了解文法開 係, 了解字的含義, 也就是了解原文的錀匙。必須 分析一润向子的文法關係, 嚴格根㨜文啮關係來

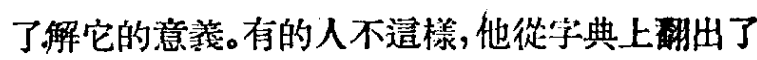

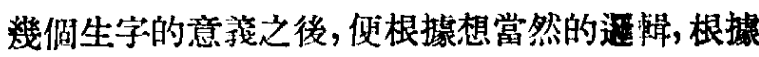
猜测，把幾個字聯賀起來，舄成句子。這是小學生 的造句,不是翻譯。可以有這樣的情况: 一㑬刉子 始終型不清它的文法關係，譯不出來; 但是不焦讋 有逭樣的情况: 並汥有䨿清一储句子的文法關係， 即根摒“渥軲”把它拼凑出來了。也還有人不管文

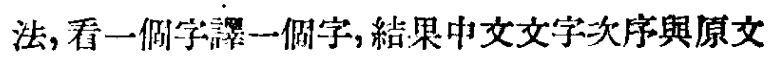

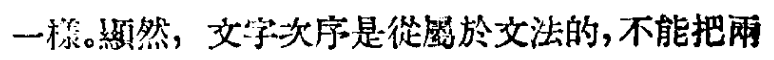
者颔倒過來。

一個字的念義常常很多, 只看字典上的第一

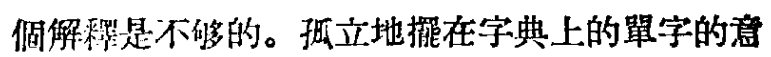

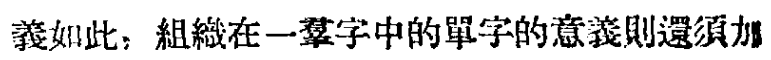
以發展、引伸、轉折。因此, 應當詳細地查一倜字的 全部解裂、查例向、查這倠字的成語, 不這樣是不 能受正学握一假字的。 
第二, 嚴格根腺文法關係與字的念義了解了 一倜句子之後, 要確切地用中文把原意傳達出來。

我們以篇，語言的交法是思惟避楫在語言中 的具能表現，思惟遇輯則是客觀事物規律的反胦， 既然客觀事物規律是全世界一致的，因而，各種語 言的交法都是相通的。䄐便是一種語文所包含的 確切意涹能够用另一種語文確切表現出來的理論 根掂：有人說原交意思㯵了，只是翻臎不出來， 将别是從科學文音的翻譯方面說來，這是浔有根 塚的。

如何用中文表現呢?我們提兩點:

倩可能筑格地按照原文文法關係來安排中 文，主菏、動詞、賓詞、各储形容詞或副詞、千句、短 語分别是形容淮的, 都不變動, 原封搬過來。當然, 这與看一個字譯一偑字毫無共通之點。

如果前面的辦法行不通, 當然便需要稍微有 些變動。造時必須特別注意, 以不變更原文含義、 不委更原文意義的重點、不變更原文提出問題的 角度第原則。翻臎本即要求嚴格, 科學書籍尤其如 此，因而作必要的變動時應硋十分慎重。前段中所 舉的例一健是由於不㥏重地變動了䆩詞, 結果由 唯物論變成唯心論, 我們應喭引以篇我。

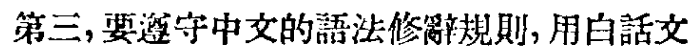
翻譯。我們要保持䇎國語言的純潔和健康, 不能 容忍看一個字譯一個字地從原文搬過來的“要死 不活的洋八股”, 不能容忍組織錯敦與不合理的句
于, 不能容㤎任意省略主語、謂語、賓語、任意省

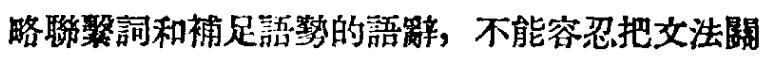
係䨿得模糊不清、含笔不明。只要努力提高自己的 中文水本, 造些都是可以反對掉的。

讀者對於科學書籍譯文之不滿，真可以說是

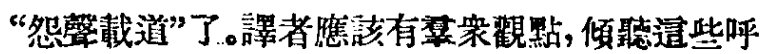

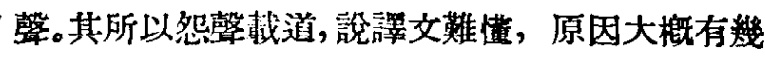
點: 第一、澤錯了，錯了自然合人不墐; 第二，不通 的交言文，文言的交法本來就不精密，不能反映現 代人的思想生活,:何况又用得不通?到了二十世紀 五十年代還用交言譯書, 從語言方面說來, 未免是 太落後了; 第三，文字欠修飾，如前段所叙达的，钟

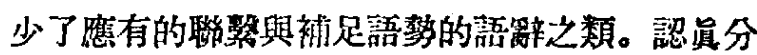
析起來, 讀者不滿之出於句子太長和外國語法的, 是很少的。由此可見譯者加强文字修辤之必要。

當然, 要求科學文字像小說一樣輕籍易讀，也 是不恰當的,科學內容本身，以及由科學內容所決 定的交字形式便決定了㯰一點。篇了追求中文更 流啺而歪曲科學內容, 當然更不容許。

以上各點，亚不是在討論高深的翻譯理論問 題，只是對目前從事科學書籍翻譯工作的同志們 提出幾點要求，乔望對實際工作有所助谷。也决不

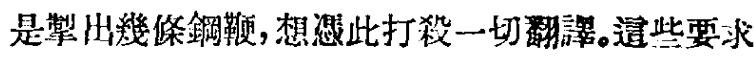
是很基本的, 應讋只會起䩿策作用。奋正認员的科 學翻譯工作者是不會害怕這種鞭策的。

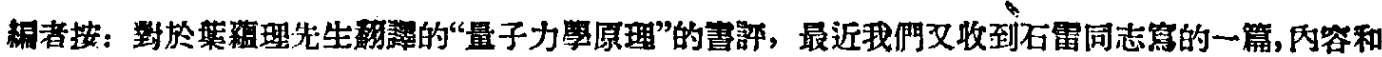

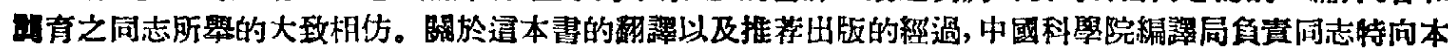
刊作如下的說明:

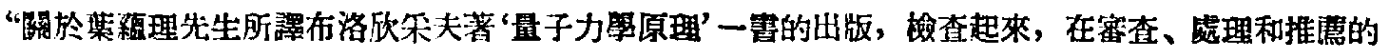

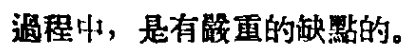

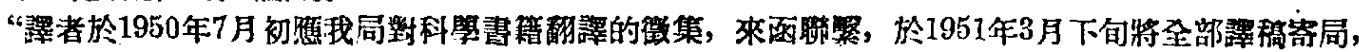

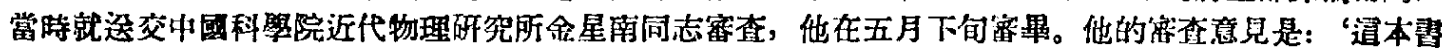

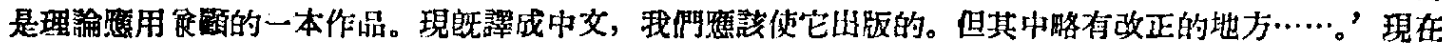

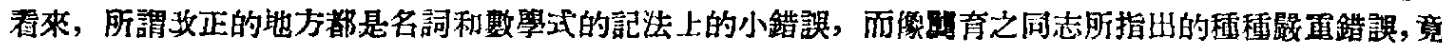

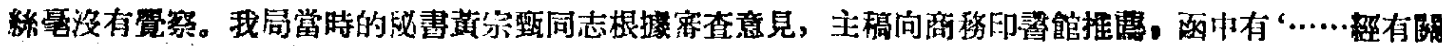

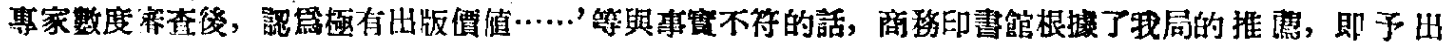
版。通樣眙誤掼者, 是很不㷳該的。

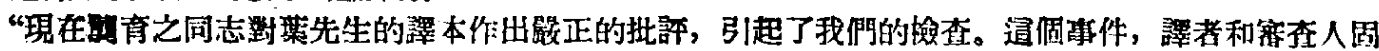

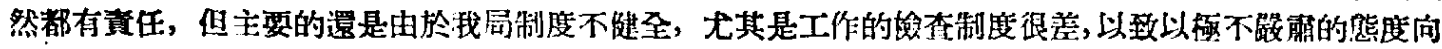

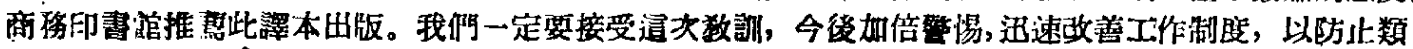
似錯㷝的再敦生。” 